Borneo Journal of Sciences and Technology, Volume (1), Issue (1), Pages: 29-32

DOI: https://doi.org/10.35370/bjost.2019.1.1-06

e-ISSN: 2672-7439

(c) 2018, UCTS Publisher.

\begin{tabular}{lll}
\hline Submitted: 31 October 2018 & Accepted: 10 November 2018 & Published: 31 January 2019
\end{tabular}

\title{
Fatigue Strength of Acacia Mangium
}

\author{
William L. N. Buglie and Mohd Shahril bin Osman \\ ${ }^{1}$ School of Engineering and Technology, University College of Technology Sarawak, \\ 868 Persiaran Brooke, 96000 Sibu, Sarawak, Malaysia
}

\begin{abstract}
The works in this study is to investigate and understand the nature of Acacia mangium axial fatigue strengths under repeated stress. Acacia mangium trees were cut to produce oven-dried Small Clear Specimens that were then tested until fracture in parallel to the grain direction. This was carried out in order to discover its Ultimate Tensile Strength, which was later identified as $143.87 \mathrm{MPa}$, in parallel to the grain direction $\left(0^{\circ}\right.$ grain angle). In the next phase, specimens were tested for fatigue strengths in repeated-tensile sinusoidal waveform loading at $100 \mathrm{~Hz}$ frequency. The stress levels for this test were at the ratios of 80, 60, 40, 30, 20 and 10\% of the Ultimate Tensile Strength $\left(0^{\circ}\right.$ grain angle) for the construction of Life $(\mathrm{N})$ - Stress $(\mathrm{S})$ plots and empirical correlation. It was observed that the Acacia Mangium N-S (Wöhler) plots have an exponential correlation with the N-intercept of vertical axis at five (5) million cycles, while the intercept of horizontal, S - axis, was at 143.87 MPa. The study also observed that Acacia mangium achieves $10^{6}$ life cycles at $10 \%$ stress level. For this reason, it is concluded that the material has a fatigue endurance limit at $10 \%$ of the Ultimate Tensile Strength for $0^{\circ}$ grain angle.
\end{abstract}

Keywords: Fatigue, Acacia, mangium, Wöhler, endurance.

\section{INTRODUCTION}

Acacia mangium is one of the most commonly planted wood species in Sarawak. It is found that no study has been done on axial fatigue strengths for solid Acacia mangium wood. Thus, the purpose of this study is to generate the S-N (Wöhler) empirical equation of Acacia Mangium species that explains the correlation between its Fatigue Strength (S) and Life Cycles (N) according to the different stress levels with $100 \mathrm{~Hz}$ frequency of controlled amplitude sinusoidal-repeated tensile stress.

A study was conducted to evaluate and compare the static and fatigue strengths of oil palm wood (OPW) with other typical Malaysian wood materials that were commonly used for furniture applications. These include Rubberwood, Light Red Meranti, Nyatoh, Sepetir and Ramin. Due to the low density of OPW, test results had shown that the material had a much lower value, in term of its fatigue resistance, compared to other materials tested in the study. The findings showed that the life cycles of over 1 million counts was achieved by OPW with stress level at $30 \%$ of the MOR. However, at $50 \%$ stress level, the cycles were reduced to 203000 . The study concluded that the allowable design stress at $40 \%$ MOR may be set for oil palm wood material [6].

An investigation of fatigue behaviour of several wood composites, such as particle board, medium- density fibreboard (MDF), oriented strand board (OSB), and plywood, was conducted as a possible basis for determining allowable design stresses for these materials. Findings concluded that, at stress levels equal to $30 \%$ of Modulus of Rupture (MOR), all materials have high life cycle ( $N \geq 10^{6}$ cycles). In general, fatigue life decreases as stress level increases, and vice versa. In particular, for furniture designs that will be utilized in a fatigue/cyclic environment, allowable design stresses may be based on values ranging from 30 to $40 \%$ of the average rupture strength (MOR) [3].

An investigation was made on fatigue strengths for two (2) species of wood, namely Scots pine (Pinus sylvestris L.) and beech (Fagus orientalis L.). The purpose of the study was to determine the allowable design stress for furniture design. The findings indicated that, at stress level of $40 \%$, the life cycle for Scots pine (Pinus sylvestris L.) was over 1 million cycles, while for the Beech (Fagus orientalis L.), the stress level was at $50 \%$. It was concluded that the allowable design stresses for Beech and Scots pine as furniture design may be set to $50 \%$ and $40 \%$ of the Modulus of Rupture (MOR) respectively. The study also concluded that, as stress level, $\mathrm{S}$, increases, the life cycle, $\mathrm{N}$, will decrease, and vice versa [7].

The ultimate compression strength is known to be less than the tensile strength in all wood species. The

\footnotetext{
Corresponding Author: William L. N. Buglie. University College of Technology Sarawak, Tel: 084-367300, Fax: 084-367301, buglie@ucts.edu.my
} 
range of endurance limit in these woods can easily be between 22 and $38 \%$ of their respective rupture strengths (MOR) [4]. Data of endurance limit or fatigue resistance of other foreign species stated above is relevant for the purpose of observing and comparing the endurance limit of the Acacia Mangium species.

\section{MATERIALS AND METHODS}

This research adopts the experimental Stress-Life method as an approach to observe the response of Small Clear Specimen of Acacia mangium wood under cyclicrepeated axial stress. Experimental procedures used were the BS 373 for specimen preparation and the ASTM E466 for fatigue testing. Specimens were tested in repeated axial-tensile loading with sinusoidal waveform.

Test specimens were produced from selected Acacia mangium trees that are 15 years of age. Thirty (30) pieces of oven-dried dog bone shaped specimens were prepared for static tensile test. For the axial fatigue test, thirty (30) pieces of oven-dried Small Clear Specimen were prepared for each pre-determined Stress Level. As there were six (6) Stress Levels required for the test, thus the total specimens required were 180 pieces.

For this study, the independent variables that were manipulated were the stress level and the grain angle. Meanwhile, the other independent variables were fixed. A series of tests were conducted to determine the fatigue strength of the material. The load fluctuated between zero and the values of the pre-determined stress levels with a frequency of $100 \mathrm{~Hz}$. Fatigue specimens were tested in six (6) different stress levels, namely 80 , $60,40,30,20$ and $10 \%$ of the Ultimate Tensile Strength parallel to the grain line $\left(0^{\circ}\right.$ grain angle $)$. The test specimens were tested at stress level that was a little less than its ultimate strength until failure occurred. This was conducted in order to determine its life cycle. The other identical specimens were tested again with the same procedure but at a lesser stress level compared to the initial test. This procedure continues with decreasing stress levels and, later, the results were plotted.

\section{RESULTS AND DISCUSSION}

A static axial-tensile test parallel to the wood grain $\left(0^{\circ}\right.$ grain angle) of a total of 30 specimens were conducted and the results showed that the Ultimate Tensile Strength $(S=)$ was $143.87 \mathrm{MPa}$. For the axial-fatigue test in the direction parallel to the wood grain $\left(0^{\circ}\right.$ grain angle), it was observed that the specimens failed at the slender section. The specimen broke into two at the angle of $45^{\circ}$ from the grain line. The nature of breakage is shown in Figure 1. All test results showed that no obvious necking on all test specimens.
The stress levels are defined as in Equation 1 below. Loads fluctuated between zero and the values of the six (6) pre-determined stress levels. Meanwhile, the results of fatigue test are shown in Table 1.

$$
\begin{aligned}
& S L=r(\%) \times S \\
& \text { With: } \\
& S L=\text { Stress Level } \\
& S==\text { Ultimate Tensile Strength parallel to the grain line } \\
& \left(0^{\circ} \text { grain angle }\right) \\
& r=\text { ratio }(80 \%, 60 \%, 40 \%, 30 \%, 20 \% \text { and } 10 \%)
\end{aligned}
$$

The finalized Acacia Mangium N-S plot as a result of the axial-fatigue test in the direction parallel to the wood grain is shown in Figure 2. In this study, it was observed that this material had the endurance strength at $10 \%$ of its ultimate tensile strength as it reached one (1) million life cycles at the aforementioned stress level. Other wood materials, such as those stated in [3, 4, 6 and 7], have endurance limits in between 25 to $38 \%$ of their respective rupture bending strengths (MOR). Malaysian wood species, such as Rubberwood, Light Red Meranti, Nyatoh, Sepetir and Ramin were also observed to have the same nature of difference between their rupture bending strengths (MOR) and their elastic bending strength (MOE). These species were tested for their bending fatigue strengths and results had indicated that they had an endurance limit at $40 \%$ of their rupture bending strengths (MOR) [6].

This may be caused by the difference in reference strength between fatigue bending and tensile fatigue tests as a basis for deriving the stress levels. Previous studies on wood fatigue were based on the rupture bending strengths (MOR) as their reference strengths that were gained from static bending tests.

In a fatigue testing situation, where the stress level is equivalent to $100 \%$ of the MOR, such condition is identical to a static bending test. In this context, a dead load is applied onto the bending specimen, and it is anticipated that the specimen will break immediately without finishing a complete cycle $(0<N<1)$. However, when observing a static bending test, where the load is equivalent to $100 \%$ MOR, specimen does not break as breakage only happens after passing the MOE value, which is very much higher. Both of these observations are contradictory and not realistic. The MOE should be used, instead of the MOR, for maintaining collateral between both observations. The usage of the MOR will censor the optimal capability of wood materials as the value of the MOE is higher (about 120 times higher than the MOR). 


\section{Acacia Mangium N-S (Wöhler) Empirical Equation}

The finalized Acacia Mangium Wöhler Life-Stress plots and empirical correlation is shown in Figure 3. The finalized equation for explaining the relationship between fatigue life cycle $(\mathrm{N})$ and stress level $(\mathrm{S})$ for Acacia mangium wood was identified as Equation 2. This correlation is also known as the Wöhler Curve. The equation is actually showing the empirical relationship between fatigue strengths and life cycles based on $0^{\circ}$ angle from the grain line.

$N=5 \times 10^{6} \cdot e^{-0.1 \cdot r \cdot S_{5}}$

With, $r=$ ratio, in percentage

$S=$ ultimate tensile strength at $0^{\circ}$ grain angle (parallel to the grain)

As observed in the $\mathrm{N}-\mathrm{S}$ plots and equation, the $\mathrm{N}$ - intercept of vertical axis is at five (5) million cycles while the intercept of horizontal, $\mathrm{S}$ - axis, is at 143.87 $\mathrm{MPa}$. However, the intersection of $\mathrm{N}$ - axis actually corresponds to zero (0) Stress Level. Therefore, the maximum life of Five (5) million cycles in reality is unachievable and invalid. Thus, the N-S equation is only applicable for Stress Level domain of:

$$
0<\text { Stress Level } \leq 143.87 \mathrm{MPa}
$$

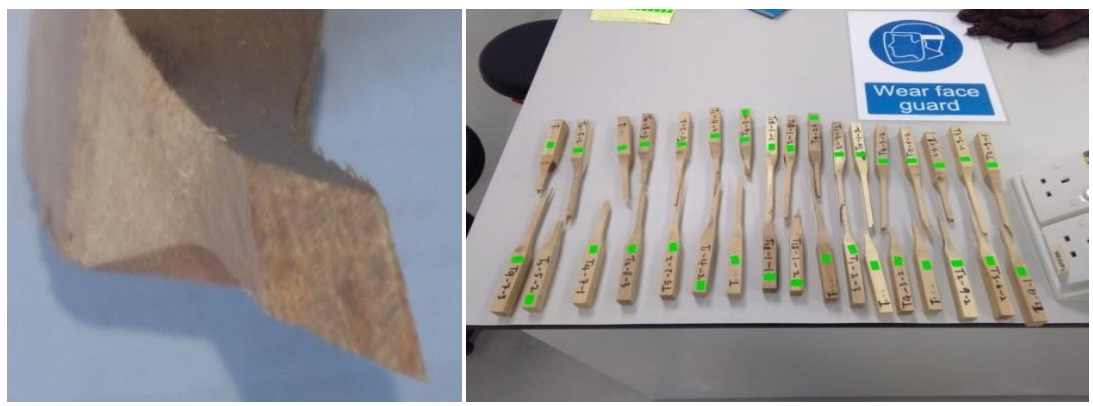

Figure 1: Nature of Breakage of Specimens Parallel to Grain

Table 1: Mean life cycle for parallel to grain fatigue test

\begin{tabular}{ccc}
\hline Ratio, $\mathrm{r}$ & Stress Level & Mean, Fatigue Life Cycle \\
\hline $80 \%$ & $115.096 \mathrm{MPa}$ & 15491 Cycles \\
$60 \%$ & $86.322 \mathrm{MPa}$ & 85495 Cycles \\
$40 \%$ & $57.548 \mathrm{MPa}$ & 159022 Cycles \\
$30 \%$ & $43.161 \mathrm{MPa}$ & 260518 Cycles \\
$20 \%$ & $28.774 \mathrm{MPa}$ & 534227 Cycles \\
$10 \%$ & $14.387 \mathrm{MPa}$ & 1043866 Cycles \\
\hline
\end{tabular}

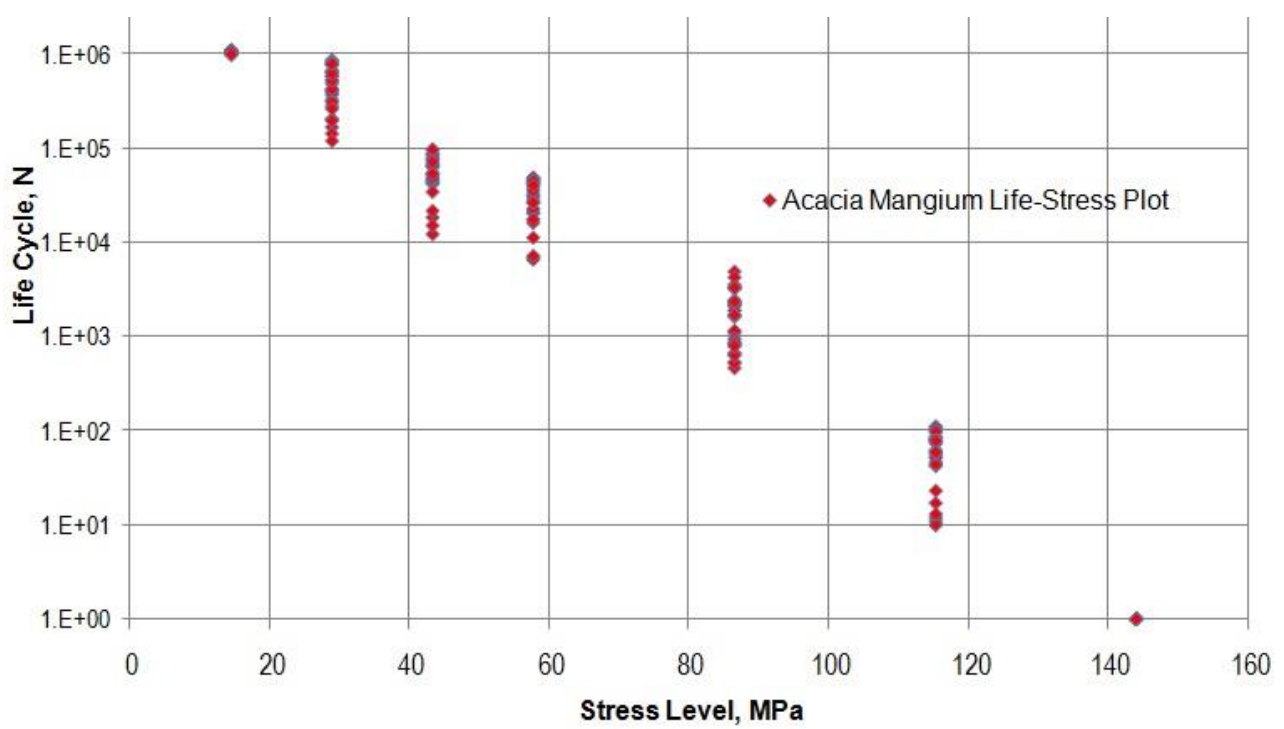

Figure 2: Acacia Mangium Wöhler (N-S) Plots 


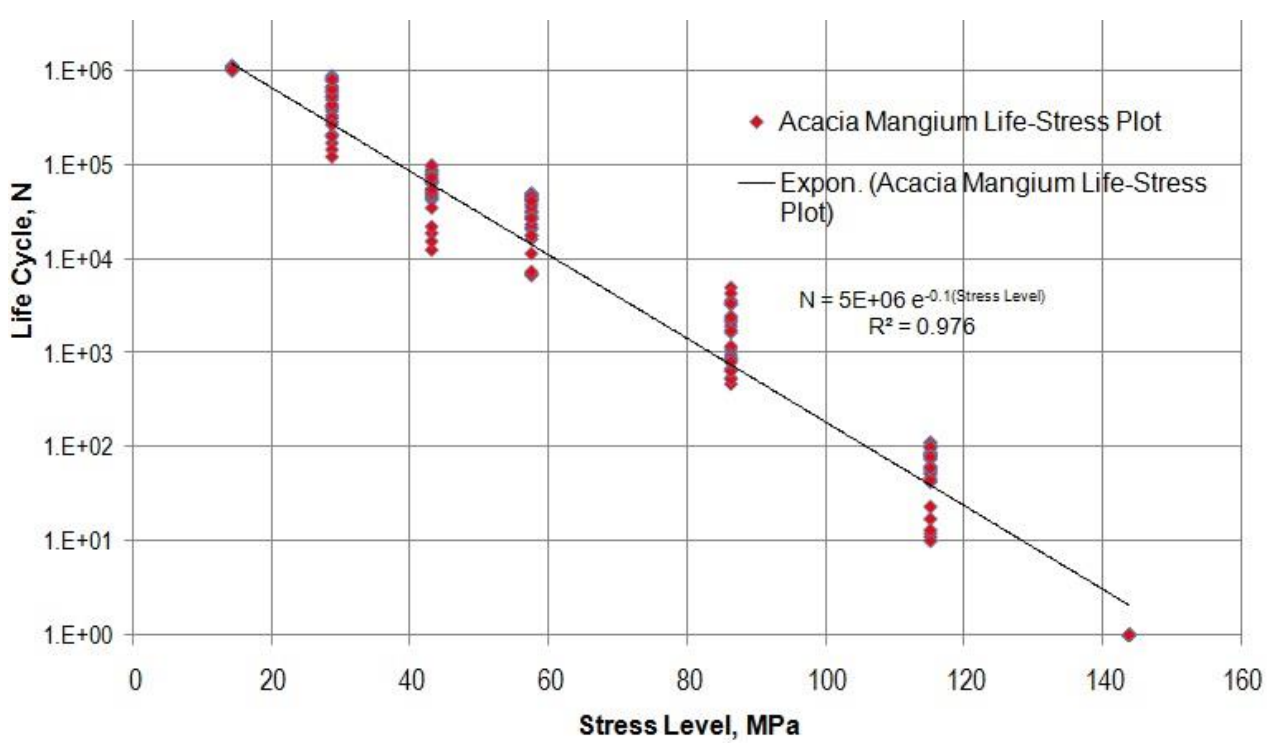

Figure 3: Acacia Mangium Wöhler (N-S) Correlation

\section{CONCLUSION}

All test results had confirmed that the Acacia mangium wood is a brittle material as no obvious necking was observed on all the fatigue specimens. All parallel to the wood grain $\left(0^{\circ}\right.$ grain angle) specimens were observed to break into two (2) different sections at the angle of $45^{\circ}$ from the load line. It was identified that the Ultimate Tensile Strength in parallel to the grain direction $\left(0^{\circ}\right.$ grain angle) was $143.87 \mathrm{MPa}$. The study also observed that the Acacia Mangium N-S (Wöhler) plots have an exponential correlation with the $\mathrm{N}$ - intercept of its vertical axis at five (5) million cycles, while the intercept of horizontal, S - axis, was at $143.87 \mathrm{MPa}$. The Acacia mangium wood achieved $10^{6}$ life cycles at $10 \%$ stress level. For this reason, it is concluded that the material has a fatigue endurance limit at $10 \%$ of the Ultimate Tensile Strength for $0^{\circ}$ grain angle.

\section{ACKNOWLEDGMENT}

The authors sincerely acknowledge and appreciate the University College of Technology Sarawak (UCTS) and Sarawak Forestry Corporation (SFC) for the support throughout the whole research process.

\section{REFERENCES}

[1] Alik, D. and Nungah, L. (2014). Mechanical properties. Proceedings of the Sarawak Forestry Corporation (SFC) \& Sarawak Timber Association (STA) Research Seminar on Basic and Working Properties of Acacia mangium planted in Sarawak. Kuching: Sarawak Forestry Corporation (SFC) \& Sarawak Timber Association (STA).

[2] American Society for Testing and Materials. (2015). Metallic materials fatigue testing procedure, ASTM E466. Pennsylvania: American Society for Testing and Materials.

[3] Bao, Z., Eckelman, C. and Gibson, H. (1996). Fatigue strength and allowable design stresses for some wood composites used in furniture. Holz als Roh- und Werkstoff, 54, pp. 377 - 382.

[4] Bodig, J. and Jayne, B. A. (1982). Mechanics of wood and wood composites $1^{\text {st }}$ edition. Florida: Krieger Publishing Company.

[5] British Standard. (1957 confirmed 2008). Method of testing small clear specimens of timber, BS 373. London: British Standard.

[6] Ratnasingam, J. and Ioras, F. (2010). Static and fatigue strength of oil palm wood used in furniture. Journal of Applied Sciences, 10 (11), pp. $986-990$.

[7] Yildirim, M. N., Uysal, B., Ozcifci, A., Ertas, A. H. (2015). Determination of fatigue and static strength of Scots pine and Beech wood. Wood Research, pp. 679 - 686. 